\title{
Animal movement in the absence of predation: environmental drivers of movement strategies in a partial migration system
}

\author{
Guillaume Bastille-Rousseau, James P. Gibbs, Charles B. Yackulic, Jacqueline L. Frair, Fredy Cabrera, \\ Louis-Philippe Rousseau, Martin Wikelski, Franz Kümmeth and Stephen Blake
}

\begin{abstract}
Animal movement strategies including migration, dispersal, nomadism, and residency are shaped by broad-scale spatialtemporal structuring of the environment, including factors such as the degrees of spatial variation, seasonality and interannual predictability. Animal movement strategies, in turn, interact with the characteristics of individuals and the local distribution of resources to determine local patterns of resource selection with complex and poorly understood implications for animal fitness. Here we present a multi-scale investigation of animal movement strategies and resource selection. We consider the degree to which spatial variation, seasonality, and inter-annual predictability in resources drive migration patterns among different taxa and how movement strategies in turn shape local resource selection patterns. We focus on adult Galapagos giant tortoises Chelonoidis spp. as a model system since they display many movement strategies and evolved in the absence of predators of adults. Specifically, our analysis is based on 63 individuals among four taxa tracked on three islands over six years and almost $10^{6}$ tortoise re-locations. Tortoises displayed a continuum of movement strategies from migration to sedentarism that were linked to the spatio-temporal scale and predictability of resource distributions. Movement strategies shaped patterns of resource selection. Specifically, migratory individuals displayed stronger selection toward areas where resources were more predictable among years than did non-migratory individuals, which indicates a selective advantage for migrants in seasonally structured, more predictable environments. Our analytical framework combines large-scale predictions for movement strategies, based on environmental structuring, with finer-scale analysis of space-use. Integrating different organizational levels of analysis provides a deeper understanding of the eco-evolutionary dynamics at play in the emergence and maintenance of migration and the critical role of resource predictability. Our results highlight that assessing the potential benefits of differential behavioral responses first requires an understanding of the interactions among movement strategies, resource selection and individual characteristics.
\end{abstract}

Animal movement strategies vary markedly, from repeated migrations, to discrete dispersal events, nomadism and sedentarism (Mueller and Fagan 2008). These movement strategies can be driven by predation or environmental factors such as temperature or food supply (pathway 1 in Fig. 1, Alerstam et al. 2003, Mueller and Fagan 2008). Sedentary strategies (i.e. restricted movement to a specific area) may be optimal in environments where resources are either fairly static or their spatio-temporal dynamics occur over scales finer than the locomotion capacity of the animal (Mueller and Fagan 2008). In contrast, a heterogeneous environment in which resource distributions are strongly differentiated over large-scales, should favor migratory strategies (i.e. movement from one area to another and back) where resources change predictably, or nomadism (i.e. movement apparent to a random walk) where resource distributions are unpredictable (Jonzén et al. 2011, Mueller et al. 2011). These hypotheses offer clear predictions regarding the expected broad-scale movement strategies for taxa living in different environments. However, testing these predictions is challenging because it necessitates detailed data on movements of many individuals from one or multiple closely related species that exhibit a suite of different movement strategies across a variation of environmental conditions that provide different and quantifiable distributions of important resources at different scales (Cagnacci et al. 2011, Mueller et al. 2011, Singh et al. 2012).

Whereas broad-scale environmental gradients are expected to influence the frequency of movement strategies among taxa, a high degree of movement variability may also be observed within a species and sometimes among spatially and temporally overlapping individuals using different 


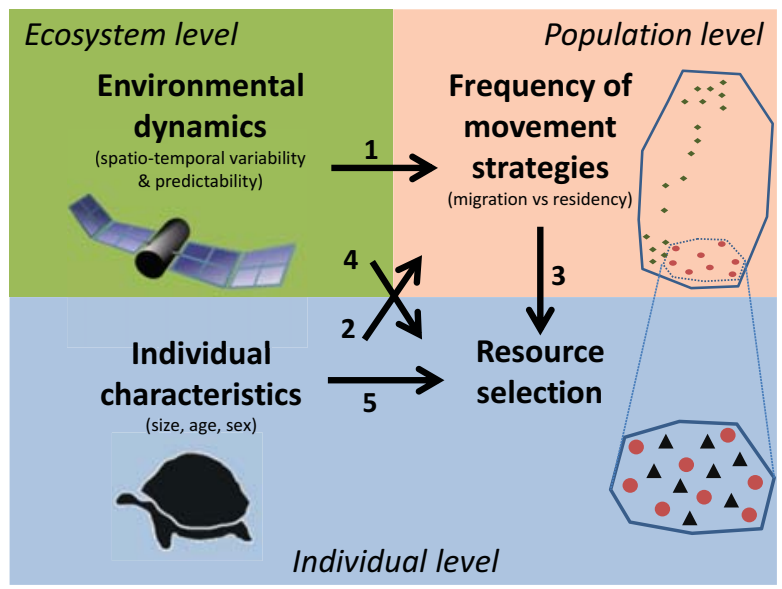

Figure 1. Pathways through which environmental dynamics and individual characteristics influence population level patterns in movement strategies and individual level of resource selection. Environmental dynamics (captured here using remote sensing data) and individual characteristics can influence the frequency of movement strategies in population (arrows 1 and 2). Different movement strategies can then have different patterns of resource selection (arrow 3) which can also be influenced by environmental dynamics and individual characteristics (arrows 4 and 5).

strategies. For example, partial migration can evolve where density dependent processes operate in combination with seasonal fluctuations in habitat suitability (Swingland and Coe 1979, Kaitala et al. 1993, Alerstam et al. 2003). Alternatively, partial migration can also be maintained when the associated benefits or ability to migrate apply to only a sub-group of individuals (see pathway 2 in Fig. 1; Boyle 2008, Singh et al. 2012, Yackulic et al. unpubl.). In partially migratory systems, resident and migratory individuals may coexist in a given area during a portion of the annual cycle (Ball et al. 2001, Jahn et al. 2010, Bischof et al. 2012, Yackulic et al. 2014) but may utilize local resources quite differently, and with different implications for individual fitness (Chapman et al. 2011). Whereas evidence is strong that movement strategies are driven by large-scale structuring of the environment (Mueller et al. 2011), less well understood is how the resource selection patterns associated with different strategies should differ when constrained to a single area (see pathway 3 in Fig. 1).

Although many studies have addressed the impact of environmental variation and patterns of resource selection (see pathways 4 and 5 in Fig. 1), in partially migratory systems it is unclear how resident versus migratory individuals should use local areas based on the availability and predictability of resources. Migration enables individuals to exploit large-scale spatio-temporal variation in resources and migratory individuals frequently outmatch their sedentary counterparts over the full annual cycle (Fryxell et al. 1988), yet, in some cases, residents may outmatch migratory individuals (Middleton et al. 2013). At fine scales, resident individuals may be expected to outmatch migrants due to knowledge of local conditions, although this too is not always the case (Ball et al. 2001, Bischof et al. 2012). Integrating broadscale analyses of movement strategies across environmental gradients with finer-scale analyses of resource selection may reconcile previous incongruities by identifying 1) the conditions that favor different movement strategies, 2) how individuals using different strategies perform under different environmental conditions, and 3) how future environmental changes should impact the frequency of different strategies (Singh et al. 2010).

Here we study a model genus, giant Galapagos tortoises Chelonoidis spp., in which predation is absent after the juvenile stage (Congdon et al. 1993), allowing us to concentrate on only the environmental drivers of movement (Blake et al. 2013). Multiple colonization events onto different islands from a single founder individual, coupled with strong environmental variation among and within islands, have led to the evolution of up to 16 different species of tortoise (Caccone et al. 2002, Poulakakis et al. 2015), of which 11 are extant and spread over six islands within the Galapagos Archipelago. Some species are known to migrate seasonally in response to vegetation productivity (Blake et al. 2013, Bastille-Rousseau et al. 2016a) with partial migration being maintained by variation in tortoise body size (Blake et al. 2013, Bastille-Rousseau et al. 2016a, Yackulic et al. unpubl.). Moreover, environmental structure in Galapagos is driven largely by topography and rainfall (Trueman and d'Ozouville 2010), which are readily quantified. Giant tortoises play important roles as ecosystem engineers, through bulldozing, grazing and seed dispersal (Merton et al. 1976, Hnatiuk 1978, Blake et al. 2012), and maintaining their populations and ecosystem function will be challenging in the face of accelerating anthropogenic change (Watson et al. 2009, Trueman et al. 2013). For these reasons the Galapagos environments and their endemic, ectothermic and herbivorous giant tortoises occurring on multiple islands in strikingly different ecological settings provides an ideal model system for studying the spatiotemporal drivers of animal movement and resource selection. We capitalize on this unique system to differentiate movement strategies by the distance, timing and duration of movements (Bunnefeld et al. 2011, Fleming et al. 2014, Bastille-Rousseau et al. 2016a) and to determine how environmental variability structures movement strategies and subsequent patterns of resource selection.

Using a combination of remote sensing data and GPStagged tortoises, we investigate how environmental variability and individual animal characteristics drive the adoption of movement strategies which, in turn, shapes resource use and selection. Previous work on a single species of giant tortoise illustrated the importance of vegetation productivity on tortoise movement (Blake et al. 2013). Because of this and because tortoises are ectotherms, we hypothesized that vegetation productivity and temperature would be the main drivers of movement. We therefore expected that migratory and non-migratory individuals will differ in their exposure to and selection of these variables. More specifically, we address the following questions: 1) to what degree is the environment structured and predictable inside the realized range of each species? 2) How does environmental structuring interact with individual characteristics to determine the frequency of distinct movement strategies within each species? 3) How does resource availability and predictability drive differences in resource use and selection between migratory and nonmigratory individuals? 4) For migratory individuals, how 
does environmental structuring drive tortoise distribution in each seasonal range?

By answering these questions, we not only reveal general mechanisms likely driving the movement patterns of a diverse set of species across a variety of spatio-temporal scales but also deepen our understanding of the ecology of iconic, yet poorly understood Galapagos tortoises. Given that protecting animal migration phenomena represents one of the greatest challenges in conservation today (Wilcove and Wikelski 2008, Middleton et al. 2013), a rigorous understanding of animal movement processes across a variety of biological scales - from individuals to species - is an urgent need.

\section{Material and methods}

\section{Study area and data collection on tortoise movements}

Giant tortoises occur on six different islands throughout the Galapagos Archipelago. Interactions between shifting ocean currents, wind direction and topography create extensive spatiotemporal gradients in temperature, precipitation and, by extension, vegetation (Trueman and d'Ozouville 2010). Islands that attain high elevations (above $1300 \mathrm{~m}$ ) have dry conditions in the highlands followed by a humid zone at intermediate elevations due to the creation of a cloud band persisting for most of the year (Trueman and d'Ozouville 2010). Islands that attain intermediate elevation only have humid highlands. Rainfall declines at lower elevations and arid lowlands dominate the terrestrial surface area of Galapagos. Two seasons are generally recognized; a cool dry season from June to November during which time highlands vegetation remain lush, and a hot wet season from December to May during which lowlands and uplands receive similar high levels of precipitation.

Between 2009-2014, we deployed custom-built GPS tags (e-obs) onto 68 adult tortoises from four species on three different islands (Santa Cruz, Espanola Island and Isabela; Fig. 2). Our tagged sample of tortoises consisted of 18 individuals (nine females, nine males) on Espanola Island ( $C$. hoodensis), 11 (six females, five males) on Isabela Island (C. vandenburghi; Alcedo Volcano population), and 39 individuals in two populations on Santa Cruz Island: 14 (seven females, seven males) from eastern Santa Cruz (C. donfaustoi) locally called 'Cerro Fatal' and 25 (17 females, eight males) from western Santa Cruz (C. porteri) in 'La Reserva' (Russello et al. 2005, Poulakakis et al. 2015). Tagged tortoises included individuals of both recognized morphotypes - 'saddlebacks' (with elevated frontal portions of the carapace, which occur on arid low-lying islands) and 'domes' (with carapaces that extend low over the head, which occur on islands with humid highlands; Fritts 1983), and varied across arid and humid habitats typical of the archipelago. Tortoises on Santa Cruz Island and Alcedo Volcano were exposed to greater variation in vegetation abundance along elevation gradients than tortoises on the topographically flat Espanola Island (Trueman and d'Ozouville 2010).
Tortoises are largely immobile at night, so to maximize battery life we programmed GPS units to record locations every hour during the day (05 a.m. - 07 p.m.) yielding 893204 tortoise locations (78-26 788 among individuals). When tags were attached, tortoise size (curved carapace length) and sex were recorded. From carapace length, we estimated tortoise mass based on island-specific allometric relationships (Bastille-Rousseau et al. 2016b). All animal handling procedures followed the guidelines of the Galapagos National Park, the Max Planck Institute of Ornithology, and IACUC protocol no. 121202 of the State Univ. of New York, College of Environmental Science and Forestry.

\section{Remote sensing data}

To quantify spatio-temporal change in environmental conditions and identify conditions that favor specific movement strategies, we used moderate resolution imaging spectroradiometer (MODIS) data from the Terra satellite (Justice et al. 1998) to quantify vegetation conditions at a resolution of $250 \mathrm{~m}$. More specifically, we derived indices from the normalized difference vegetation index (NDVI), which reliably relates to vegetation productivity and resources available to herbivores (Pettorelli et al. 2005, Hebblewhite et al. 2008, Mueller and Fagan 2008). NDVI data were acquired as 16-day composites, yielding 23 composites per year from 2000-2015. To correct for NDVI errors induced by clouds and other sources, we performed iterative interpolation data reconstruction following Julien and Sobrino (2010). Within one annual time-series, for each pixel on a given day, an 'alternative' NDVI value was computed as the mean between the immediately preceding value (16 days earlier) and the following value (16 days later). Missing data were also replaced with the mean of the preceding and following values. NDVI errors were identified when the alternative NDVI value differed from the observed value by 0.02 units. Correcting these errors was an iterative process. First, we identified the date of maximum difference, and for all pixels on that day where errors were identified, the alternative NDVI value replaced the observed value. Next, a new time series of alternative NDVI values was computed from the modified time series, errors were corrected on the date of maximum difference, and the process was iterated until no more errors were detected (see Julien and Sobrino 2010 for further details). This approach was deemed more appropriate than a parametric fit, such as the double logistic approach (Hird and McDermid 2009), given that we did not have strong a priori expectations for seasonal variation in vegetation development, especially for highland areas where productivity can be relatively homogenous in time (Blake et al. 2013).

Because tortoises are ectothermic, temperature differences may drive movement decisions and interact with their foraging requirement. Therefore, we acquired nightly land surface temperature (LST) values at a $1-\mathrm{km}$ resolution from the Terra satellite. Night-time LST values were considered less biased by vegetation structure and earth emissivity than day-time values (Wang et al. 2008). Given the high number of pixels with unreliable values due to cloud cover, we 

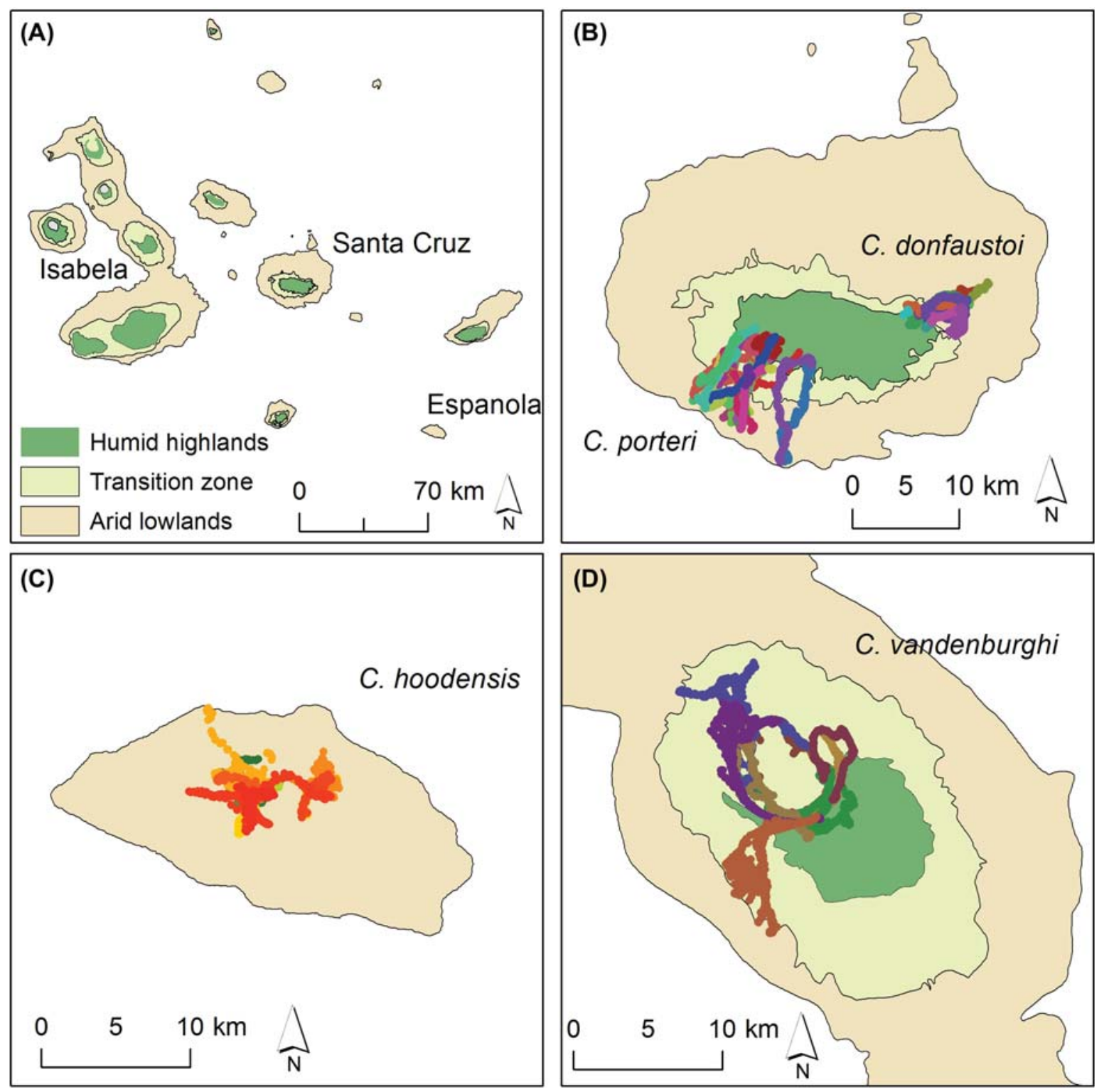

Figure 2. Population ranges of 63 adult giant tortoises included in this study from four different taxa inhabiting the Galapagos Islands, 2009-2014. (A) The Galapagos Archipelago, illustrating vegetation zones, (B) Santa Cruz Island, including tortoise tracks and of the western (C. porteri) and eastern (C. donfaustoi) regions, $(\mathrm{C})$ tortoise tracks on Espanola Island (C. hoodensis), (D) tortoise tracks on Alcedo Volcano (C. vandenburghi) on Isabela Island.

averaged nightly composites on a bi-weekly basis and kept only cloud free pixels, yielding 26 composites per year. These LST values compared favorably with temperatures averaged bi-weekly by local weather stations (Pearson $r=0.79-0.91$ by island; $n=4$ stations, Supplementary material Appendix 1 Fig. A1). Given that NDVI and LST values were available at 16-day and 14-day composites respectively, we used a spline function to interpolate daily location values between the different composites so as to extract these values specific to each daily tortoise location. Using a spline also allowed us to estimate daily rate of change in vegetation greenness from NDVI. This metric is regularly used as an index of vegetation quality (Pettorelli et al. 2007, Bischof et al. 2012) and has been shown to be strongly selected for by numerous herbivores (Merkle et al. 2016).

\section{Quantifying spatio-temporal structure within species ranges (question 1)}

For both NDVI and LST, we quantified seasonality (intraannual variability), predictability (inter-annual variability in spatial and seasonal patterns; Mueller and Fagan 2008), and spatial pattern within the range of each species over the last 15 years. We defined the range of each species as the minimum convex polygon encompassing all tagged tortoise locations within the population (we use 'range' throughout to refer to the overall area occupied by a species, either on an annual or seasonal basis). Due to our modest sample of tagged tortoises relative to overall population size, we are likely under-estimating the true distribution of each species, but this approach allowed us to make valid inferences 
on the environmental conditions to which tagged tortoises were exposed. To represent seasonality, we calculated the mean NDVI and LST within each species range for each 16-day period for both environmental variables $z$ following:

$$
\bar{x}_{d r}=\frac{\sum_{i=1}^{n_{r}} \sum_{y=2001}^{2015} \frac{Z_{i y d r}}{15}}{n_{r}}
$$

where $d$ is the Julian day of a composite, $r$ is the range of one of the four species containing $n_{r}$ pixel $i$, and $y$ is a year between 2001-2015. To quantify predictability, we first calculated, for a given pixel, the standard deviation of NDVI and LST across all years on that day. Then we averaged standard deviation values within each species range on that day to represent the bi-weekly predictability of each variable. Consistent with previous notation, this is given by:

$\bar{\sigma}_{d r}=\frac{\sum_{i=1}^{n(r)} \sqrt{\sum_{y=2001}^{2015} \frac{\left(Z_{i y d r}-\overline{Z_{i d r}}\right)^{2}}{15-1}}}{n}$

where $\overline{Z_{\imath d}}$ represents the across year average of an environmental variable for a specific pixel $i$ and day $d$. To quantify spatial pattern, we calculated the inter-annual average of each 16-day composite of semi-variograms for NDVI and LST across lag distances from $500 \mathrm{~m}$ to $11 \mathrm{~km}$ within each species range. Spatial-variograms express the degree of similarity between points as a function of distance. Smaller semi-variance is associated with stronger spatial dependency whereas larger semi-variance is associated to weak spatial similarity. Following previous notation the average semivariance of a specific species range and lag and for a given day $\hat{\gamma}_{\text {rdh }}$ is:

$\hat{\gamma}_{r d h}=\frac{1}{15} \sum_{y=2001}^{2015}\left[\frac{1}{2 \times N(b)} \sum_{i=1}^{N(h)-1}\left(Z_{i y d r}-Z_{i y d r+h}\right)^{2}\right]$

where $z_{i y d r}$ is the value at location $i$ in a species range $r$ on day $d$ and year $y, z i y d r+h$ is the value of a point at a lagged distance of $h$ from pixel $i$, and $N(h)$ is the number of pairs examined at lag distance $h$. We used different maximum lags for each species range based on the movement extent of each species.

\section{Characterizing movement strategies (question 2)}

We resampled animal trajectories to one location/day, defined as the average easting and northing coordinates of all hourly locations from that day. For 63 tortoises having 200-1591 days of monitoring, we applied a clustering algorithm to characterize intra- and inter-annual movement patterns to classify movement strategies following the methods of Bastille-Rousseau et al. (2016a). Our approach involved calculating the daily net-squared displacement (NSD; Bunnefeld et al. 2011) for each individual, and fitting the NSD time series with a mixture-model of two normal distributions (to identify clusters 1 and 2, which for dispersal and migratory individuals represented two discrete ranges) and one pseudo-uniform distribution (identifying a third cluster that characterized transitions between clusters 1 and 2). Ultimately, we quantified the probability of remaining in cluster $1\left(q_{11}\right), 2\left(q_{22}\right)$, or $3\left(q_{33}\right)$ between time steps, as well as the number of transitions from clusters 1 and 2, and used these values to classify movement strategies. We provide details of the classification in the Supplementary material Appendix 1.

We tested if the frequency of strategies differed among species or between sexes using a Fischer's exact test (Zar 2009). Although tortoise mass differs considerably among species and between sexes, our selection of individuals to tag was not completely random with a bias toward females on Santa Cruz. This limited our ability to make statistical inferences regarding the influence of sex on movement strategies. Nevertheless, we evaluated qualitative patterns related to body size.

\section{Individual-level analysis of space-use and resource selection (question 3 and 4 )}

For each daily tortoise location, we extracted the corresponding NDVI and LST values. We further quantified for each location the predictability of NDVI and LST, and the rate of change in vegetation greenness, by Julian day (see Quantifying landscape dynamics section).

\section{Resource use}

We first compared the differential use of current NDVI and LST, predictability of NDVI and LST, and rate of change of NDVI across different groups of tortoises. To do so, we created 10 equal-sized bins based on the range of observed values. For each individual and variable, we evaluated the proportion of locations falling into each bin. For non-migratory individuals, we included all locations across the annual cycle. For migratory individuals, the clustering algorithm associated each location with three different states: two states corresponding to seasonal ranges and the third related to the migratory journey of an individual (Bastille-Rousseau et al. 2016a). We used this framework to select out only those locations corresponding to seasonal ranges. For eastern and western Santa Cruz tortoises, we calculated the average elevation of locations for each of the two ranges, considering the lower elevation range to be the 'warm season' range. For Alcedo Volcano, we associated the state with locations closest to the south-eastern section of the crater rim to the 'cool season' range and the other state to the 'warm season' range. This 'cool season' range is expected to be cloud-covered for most of the year whereas the warm season range will be more variable across the year (Trueman and d'Ozouville 2010, Blake et al. 2013). For migratory individuals, we evaluated the proportion of locations falling into each bin separately for cool versus warm season locations.

\section{Annual resource selection}

To better understand how local exposure to fluctuations in vegetation and temperature influences resource use, we compared resource selection between migratory and nonmigratory individuals. We estimated a resource selection function using a conditional design (Boyce et al. 2002, Boyce 2006), where every daily location was paired with 10 random locations drawn within the annual range of the individual. For each used and random location, we extracted the corresponding current NDVI and LST and predictability of 
NDVI and LST corresponding to this day. We then averaged all daily values at the monthly level (i.e. the conditional design is therefore based on one monthly value defining use value and one monthly value defining availability). We selected a monthly resolution instead of a daily resolution given the resolution of our spatial data $(250 \mathrm{~m}$ and $1 \mathrm{~km})$ versus distance travelled by tortoise (hourly average $=16 \mathrm{~m}$, daily average $=72 \mathrm{~m}$, Bastille-Rousseau unpubl.). We included a quadratic term for temperature to enable non-linear responses of tortoise to this variable given their ectothermic nature should make them prefer intermediate temperature (Stevenson 1985). Our set of candidate models included the independent (current value of a variable and predictability of the variable), additive or interactive effects of NDVI and LST on resource selection by tortoises (Table 1) and a random structure including individual nested within island. We also added a null (intercept only) model, therefore given seven different models. We added a null model in our model selection to insure that the top-model identified was not spuriously selected but rather had support (Burnham and Anderson 2002). We fitted models separately for migratory and non-migratory individuals using a conditional logistic regression to compare how overall movement strategies may drive differences in resource selection patterns. We used the second-order Akaike information criteria (AICc; Burnham and Anderson 2002) to assess which model(s) provided the best fit for each movement strategy.

\section{Seasonal range selection for migrants}

To further dissect the resource selection pattern of migratory individuals, we conducted additional analyses to determine the resources that tortoises select when transitioning to the cool and warm season ranges. Our goal was not to look at within-range selection (second-order; Johnson 1980), but to understand the conditions that drive individuals to migrate to a specific range. Doing so required us to refine our contrast in the use-availability comparison by developing definitions of availabilities that expand beyond the traditional assessment based on random sampling (Bastille-Rousseau et al.
2015). We first investigated factors promoting selection for the cool season range. We associated each daily location of an individual in their cool season range with five randomlychosen locations used by that individual within their warm season range (hereafter 'random' locations). We assigned to those random locations the date of the corresponding used location, and then extracted current NDVI and LST for each location. We considered a continuous series of locations in the cool range as an 'event' and averaged the extracted value at the event level (e.g. an event can be the entire period an individual spent in the cool range in a given year before migrating). We choose a different definition of 'event' than in the previous analysis in order to better capture fine scale change in migration that can happen within a month. Similarly, we assert that using a coarser resolution (i.e. event) instead of a daily resolution for both analyses is more appropriate given the coarse resolution of our spatial data relative to tortoise movement.

Likewise, we evaluated selection of the warm season area, associating each daily location for an individual in their warm season range with five randomly-chosen used locations from their cool season range, assigning the date of the used location to the random locations, and extracting the corresponding NDVI and LST for each location. For this analysis we also extracted the rate of change of vegetation because we hypothesized that individuals may be attracted to warm season ranges due to higher vegetation quality. Furthermore, we associated each location of an individual in the warm season range with five random locations drawn within the warm range but assigning to those locations dates associated with their use of the cool season range. For this second comparison, we extracted the same variables (NDVI, LST and rate of change in vegetation) and again considered the event (the continuous period spent in the warm range) as the unit of our analysis, averaging variables at the 'event' level.

For each definition of used and random locations, we fitted mixed-effects conditional logistic regression models with individual nested within species as the random structure. We compared two hypotheses for selection of the cool season

Table 1. Candidate models of annual resource selection for 37 migratory and 26 non-migratory Galapagos giant tortoises, 2009-2014, in response to the normalized difference vegetation index (NDVI) and land surface temperature (LST). Current values and predictability of each variable were tested. Numbers of parameters $(K)$, difference in the second-order Akaike information criteria $(\triangle \mathrm{AICc})$, and $\mathrm{AIC}$ weight $(\omega \mathrm{AICC})$ are presented.

\begin{tabular}{|c|c|c|c|c|}
\hline Model & & K & $\Delta \mathrm{AIC}_{\mathrm{c}}$ & $w$ \\
\hline \multicolumn{5}{|c|}{ Migratory individual } \\
\hline 1 & $\mathrm{NDVI}_{\text {current }}+\mathrm{NDVI}_{\text {predictability }}$ & 4 & 271.90 & 0 \\
\hline 2 & $\mathrm{LST}_{\text {current }}+\mathrm{LST}_{\text {current }}^{2}+\mathrm{LST}_{\text {predictability }}$ & 5 & 286.74 & 0 \\
\hline 3 & $\mathrm{NDVI}_{\text {current }}+\mathrm{LST}_{\text {current }}+\mathrm{LST}_{\text {current }}^{2}+\mathrm{NDVI}_{\text {predictability }}+\mathrm{LST}_{\text {predictability }}$ & 7 & 110.54 & 0 \\
\hline 4 & $\mathrm{NDVI}_{\text {current }} \times \mathrm{LST}_{\text {current }} \times \mathrm{LST}_{\text {current }}+\mathrm{NDVI}_{\text {predictability }}+\mathbf{L S T}_{\text {predictability }}$ & 9 & 0.00 & 1 \\
\hline 5 & $\mathrm{NDVI}_{\text {current }}+\mathrm{NDVI}_{\text {predictability }}+\mathrm{LST}_{\text {current }}+\mathrm{LST}_{\text {predictability }}$ & 6 & 204.92 & 0 \\
\hline 6 & $\mathrm{NDVI}_{\text {current }} \times \mathrm{LST}_{\text {current }}+\mathrm{NDVI}_{\text {predictability }}+\mathrm{LST}_{\text {predictability }}$ & 7 & 82.87 & 0 \\
\hline 7 & Null (intercept) & 2 & 521.50 & 0 \\
\hline \multicolumn{5}{|c|}{ Non-migratory individual } \\
\hline 1 & $\mathrm{NDVI}_{\text {current }}+\mathrm{NDVI}_{\text {predictability }}$ & 4 & 55.07 & 0 \\
\hline 2 & $\mathrm{LST}_{\text {current }}+\mathrm{LST}_{\text {current }}^{2}+\mathrm{LST}_{\text {predictability }}$ & 5 & 54.13 & 0 \\
\hline 3 & $\mathrm{NDVI}_{\text {current }}+\mathrm{LST}_{\text {current }}+\mathrm{LST}_{\text {current }}^{2}+\mathrm{NDVI}_{\text {predictability }} \mathrm{LST}_{\text {predictability }}$ & 7 & 12.82 & 0 \\
\hline 4 & $\mathrm{NDVI}_{\text {current }} \times \mathbf{L S T}_{\text {current }} \times \mathbf{L S T}_{\text {current }}+\mathrm{NDVI}_{\text {predictability }}+\mathbf{L S T}_{\text {predictability }}$ & 9 & $\mathbf{0 . 0 0}$ & 1 \\
\hline 5 & $\mathrm{NDVI}_{\text {current }}+\mathrm{NDVI}_{\text {predictability }}+\mathrm{LST}_{\text {current }}+\mathrm{LST}_{\text {predictability }}$ & 6 & 56.47 & 0 \\
\hline 6 & $\mathrm{NDVI}_{\text {currrent }} \times \mathrm{LST}_{\text {current }}+\mathrm{NDVI}_{\text {predictability }}+\mathrm{LST}_{\text {predictability }}$ & 7 & 32.76 & 0 \\
\hline 7 & Null (intercept) & 2 & 94.87 & 0 \\
\hline
\end{tabular}


range: tortoises migrate to the cool range 1) because productivity in the cool range is higher, or 2) because increased temperature in the warm range make these areas less preferable to tortoises. We also tested a combined effect of productivity and temperature and a null model (intercept only), giving a total of four candidates models (Table 2). For selection of the warm season range, we tested four different hypotheses: tortoises migrate to the warm range 1) when productivity is increasing in the warm range and quality is high relative to the cool area, 2) because productivity is higher than in the cool range, 3) because temperature is warmer than in the cool area, and 4) when temperature is colder than in the cool area. We combined each hypothesis based on productivity with each hypothesis based on temperature and also tested each vegetation hypothesis alone, giving a total of six candidate models. We also added a null model and used $\mathrm{AIC}_{\mathrm{c}}$ to select the best fit model(s) for each season.

\section{Data deposition}

Movement data from the Galapagos Tortoise Movement Ecology Programme used here are archived and freely available on Movebank (<www.movebank.org >) (Bastille-Rousseau et al. 2016c). Environmental data and RSFs tables are available on Figshare (Bastille-Rousseau et al. 2016d).

\section{Results}

\section{Environmental structuring within the range of each species}

Tortoise species range on Espanola Island had lower overall productivity and higher overall temperatures than areas occupied by tortoises on Santa Cruz Island (Fig. 3A-B). Ranges inhabited by the two tortoise species on Santa Cruz Island (eastern versus western Santa Cruz Island) showed the highest overall levels of productivity and were intermediate in terms of temperature. Tortoise range on Alcedo Volcano showed the lowest overall temperatures. Temporal predictability in productivity varied markedly among species, with the most (western Santa Cruz Island and Alcedo Volcano) and least (Espanola Island) predictable periods co-occurring between ca February-May (Fig. 3C). Tortoise range on Espanola Island was the least predictable in terms of vegetation during the first half of the year while temperature was less predictable later in the season (Fig. 3C-D). Across species, temperature was most predictable during March and April. Predictability of vegetation productivity decreased linearly with the mean on Espanola Island, but non-linearly on the other islands indicating greater predictability at lower and higher overall levels of productivity (Fig. 3E). Colder temperatures were generally more predictable than warmer temperatures (Fig. 3F).

Spatio-temporal variability in vegetation productivity, evaluated from semi-variance, was greatest on Alcedo Volcano, intermediate on eastern and western Santa Cruz Island, and lowest on Espanola Island (Fig. 4A). Variability generally increased with spatial scale. Variability was also generally higher in the second half of the year, except for Espanola Island. Alcedo Volcano exhibited the most pronounced spatio-temporal variability in temperature, which also increased with spatial scale and was highest later in the year (Fig. 4B). In contrast, little spatio-temporal pattern was evident for temperature on the other islands.

\section{Characterizing movement strategies}

Overall, $58.7 \%$ of tortoises were migratory, $25.4 \%$ were resident, $14.3 \%$ were nomadic, and only $1.6 \%$ (one tortoise) dispersed (Fig. 5). The proportion of the population exhibiting each strategy varied markedly across islands $(\mathrm{p}<0.001)$, and to a much lesser degree between species on the same island (Santa Cruz Island, Fig. 5), but with no differences evident between the two sexes $(\mathrm{p}>0.999)$. The Alcedo Volcano tortoises $(\mathrm{n}=11)$ were all migratory (Fig. 5). In contrast, the majority of tortoises from Espanola Island were resident, with some $(16.7 \%)$ being nomadic (Fig. 5). The majority of Santa Cruz Island tortoises were migratory (69.2 and $77.3 \%$ for the eastern and western species respectively), with $15.4 \%$ and $18.2 \%$ being nomadic in eastern and western Santa Cruz Island, respectively. In eastern Santa Cruz Island, only one disperser and one resident were identified whereas none were classified in this category

Table 2. Candidate models of seasonal resource selection for 37 migratory giant tortoises, 2009-2014, in response to the normalized difference vegetation index (NDVI) and land surface temperature (LST). For models regarding selection of cool area, availability was define based on availability in the tortoise warm range. For models regarding selection of the warm range, availability was either defined based on availability in the tortoise cool range (vs cool) or based on availability in the warm range when tortoise are absent from it (vs warm). Numbers of parameters $(\mathrm{K})$, difference in the second-order Akaike information criteria $(\triangle \mathrm{AICC})$, and AIC weight ( $\omega \mathrm{AICC})$ are presented.

\begin{tabular}{|c|c|c|c|c|}
\hline Model & & $\mathrm{K}$ & $\Delta \mathrm{AIC}_{\mathrm{c}}$ & $w$ \\
\hline \multicolumn{5}{|c|}{ Cool area selection } \\
\hline 1 & $\mathrm{NDVI}_{\mathrm{vs}}$ Warm & 3 & 3.70 & 0.14 \\
\hline 2 & $\mathrm{LST}_{\text {vs Warm }}$ & 3 & 53.30 & 0.00 \\
\hline 3 & $\mathrm{NDVI}_{\mathrm{vs} \text { Warm }}+\mathrm{LST}_{\mathrm{vs} \mathrm{Warm}}$ & 4 & 0.00 & 0.86 \\
\hline 4 & Null (intercept) & 2 & 86.75 & 0.00 \\
\hline \multicolumn{5}{|c|}{ Warm area selection } \\
\hline 5 & $\mathrm{NDVI}_{\mathrm{vs} \mathrm{Warm}}+$ RateNDVI $_{\text {vs Cool }}+\mathrm{LST}_{\mathrm{vs} \mathrm{Cool}}$ & 5 & 0.00 & 0.63 \\
\hline 6 & NDVI $_{\text {vs Warm }}+$ RateNDVI ${ }_{\text {vs Cool }}+$ LST $_{\text {vs Warm }}$ & 5 & 1.13 & 0.36 \\
\hline 7 & $\mathrm{NDVI}_{\mathrm{vs} \mathrm{Cool}}+\mathrm{LST}_{\mathrm{vs} \mathrm{Cool}}$ & 4 & 20.87 & 0.00 \\
\hline 8 & $\mathrm{NDVI}_{\mathrm{vs} \mathrm{Cool}}+\mathrm{LST}_{\mathrm{vs} \text { Warm }}$ & 4 & 38.74 & 0.00 \\
\hline 9 & $\mathrm{NDVI}_{\mathrm{vs} \text { Warm }}+$ RateNDVI $_{\mathrm{vs} \text { Cool }}$ & 4 & 9.43 & 0.00 \\
\hline 10 & $\mathrm{NDVI}_{\mathrm{vs} \mathrm{Cool}}$ & 3 & 41.92 & 0.00 \\
\hline 11 & Null (intercept) & 2 & 62.39 & 0.00 \\
\hline
\end{tabular}



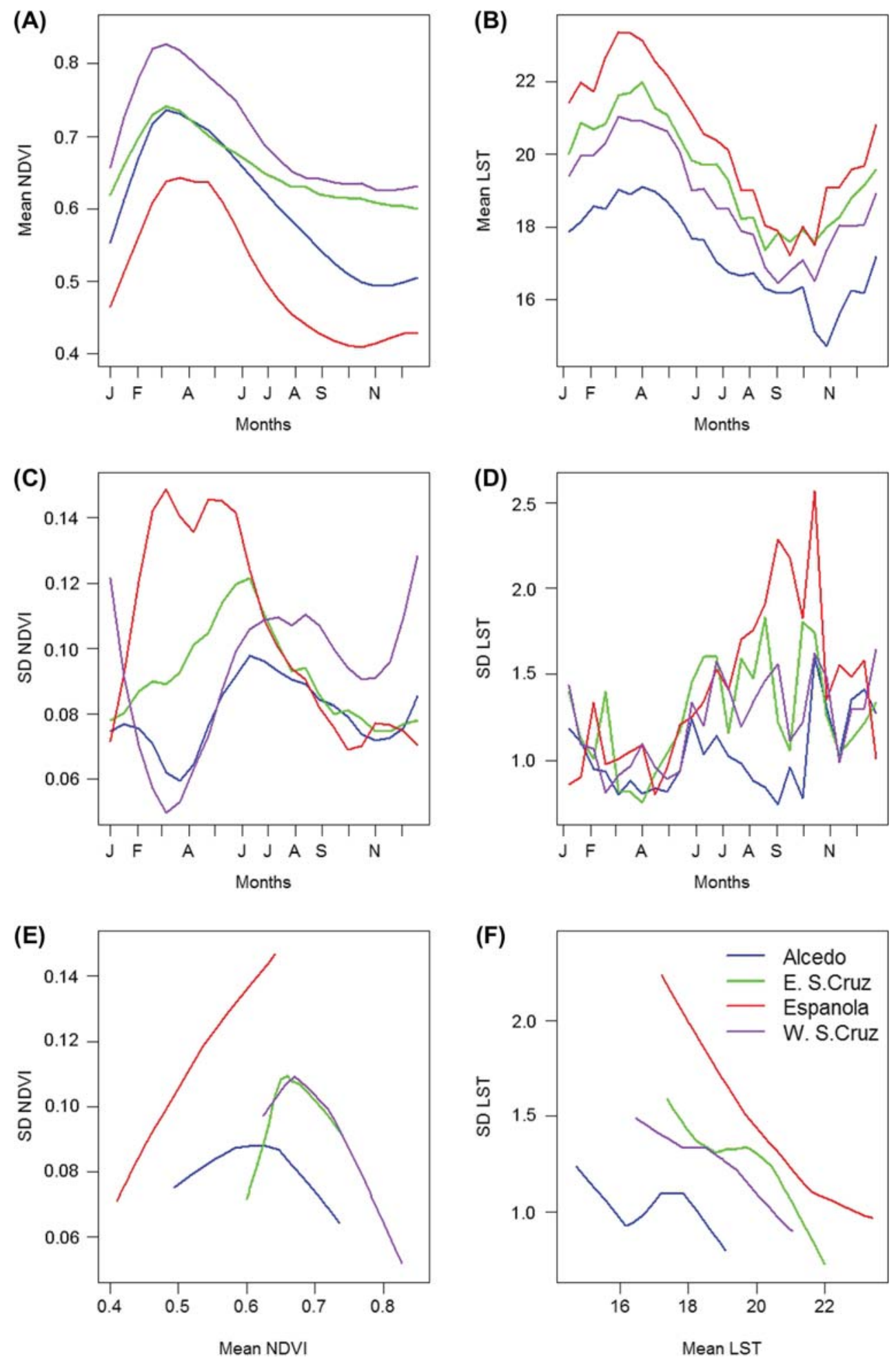

Figure 3. Comparison of landscape dynamics for four species of giant tortoises in terms of vegetation biomass (NDVI) and land surface temperature (LST) based on 14 years, 2001-2014, of MODIS Terra satellite data. (A) and (B) represent the temporal averages, (C) and (D) represent the temporal predictability and (E) and (F) represent the relationship between the average NDVI or LST and their associated predictabilities.

within the western Santa Cruz Island species. Whereas resident individuals spent little time on average in a confined area (but rather switched frequently between areas), migratory individuals spent longer continuous amounts of time between two confined areas (Supplementary material Appendix 1 Fig. A2). Among and within species, there was no clear pattern in terms of average continuous time spent in the cool or warm range (Supplementary material Appendix 1 Fig. A2). Qualitatively, our data indicate that the likelihood of adopting a migratory strategy 

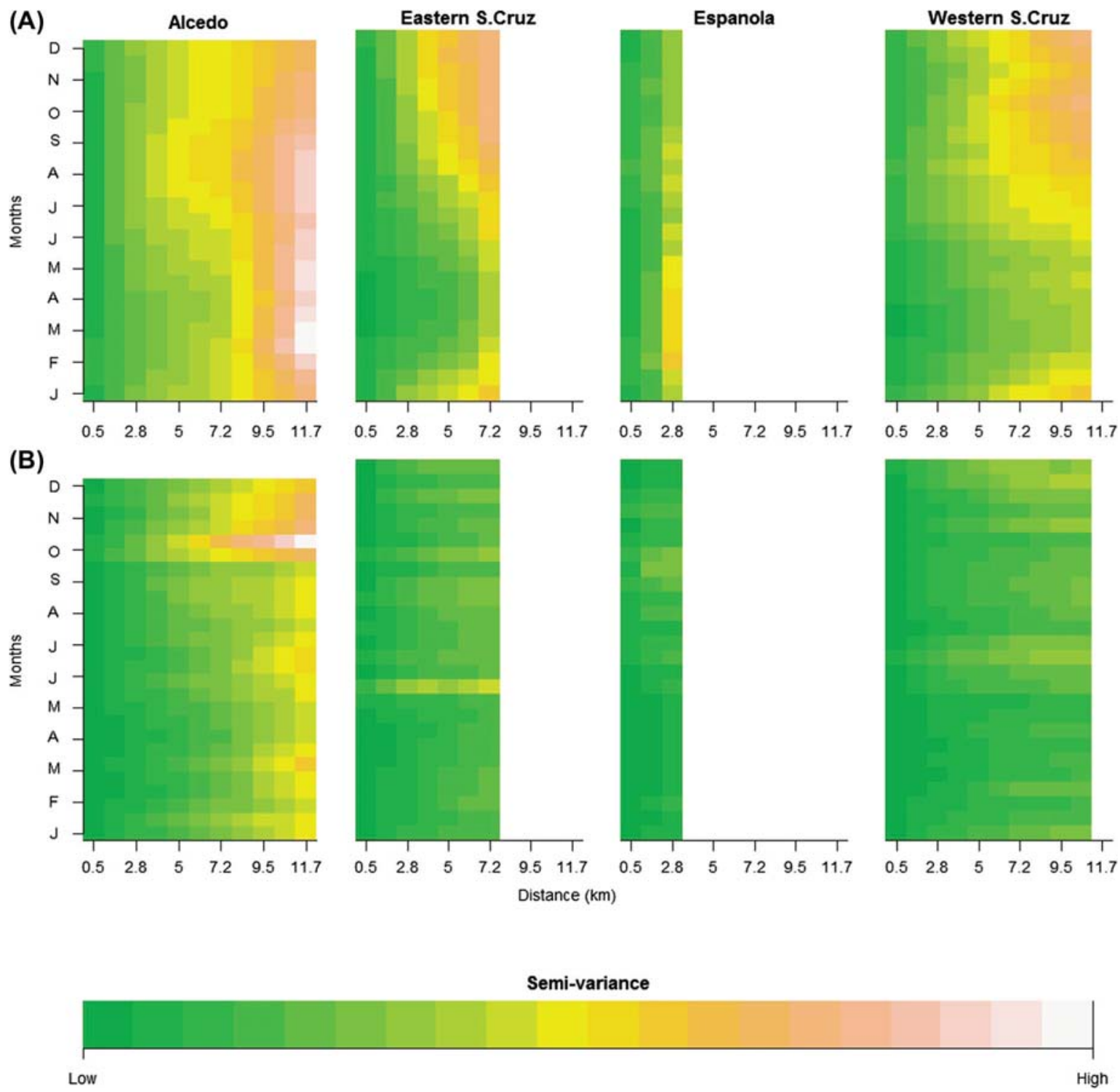

Figure 4. Semi-variance of vegetation productivity (A) and land surface temperature (B), based on 14 years, 2001-2014, of MODIS Terra satellite data for resource landscapes of four species of giant tortoises in Galapagos. Semi-variance was calculated based on the maximum movement range of each species.

increases with body size (Supplementary material Appendix 1 Fig. A3).

The trajectories of migrations were also variable within and between species. In western Santa Cruz Island, migrations were consistently linear between uplands and lowlands, spanning 0-420 m elevation and covering a maximum linear distance of $10 \mathrm{~km}$ (Fig. 2B). In eastern Santa Cruz Island, migrations were either linear or in some cases curvilinear, and generally covered much shorter distance $(<5 \mathrm{~km})$ than western Santa Cruz Island migrations (Fig. 2B). In contrast, migrations on Alcedo Volcano were characterized by semicircular movements around the rim of the caldera (Fig. 2D), with a linear displacement not exceeding $12 \mathrm{~km}$ but with actual paths exceeding $25 \mathrm{~km}$, often following long permanent tortoise trails. Some tortoises descended into the crater, while others descended outside of the volcano to more arid areas. All tagged tortoises on Alcedo Volcano selected the southeast rim of the caldera as their cool season range, which consistently exhibited the coolest temperature and highest humidity across the volcano.

\section{Resource use}

Resource use was similar between migratory and non-migratory individuals (Fig. 6). In general, tortoise from all species used areas in which NDVI was high but not maximal (Fig. 8A), temperatures were in the mid-range of availability (Fig. 6B), productivity was consistent (i.e. 0 rate of change, Fig. 6C), and NDVI and temperature were relatively predictable (Fig. 6D-E, respectively). Tortoise ranges during the cool season were greener, cooler, and more predictable than warm season ranges. With few exceptions, non-migratory tortoises sought conditions most similar to the warm season ranges used by migrants (Fig. 6). For NDVI, temperature, rate of change of NDVI, and predictability of temperature, these patterns held across the three species where migration 
(A)

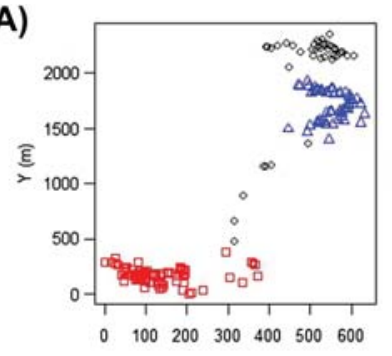

(B)

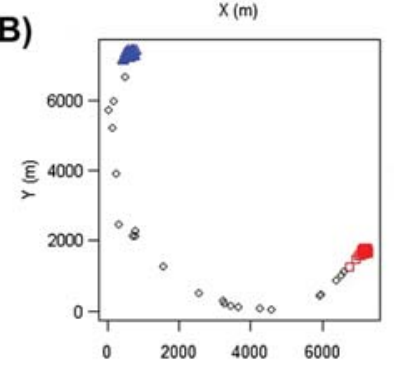

(C)

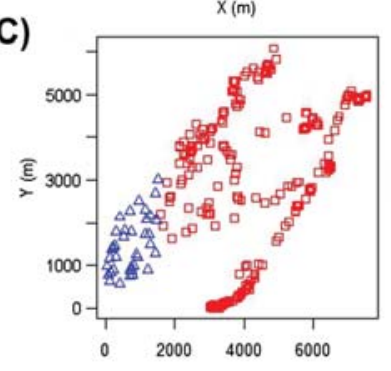

(D)

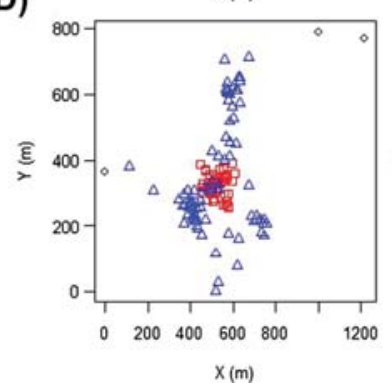

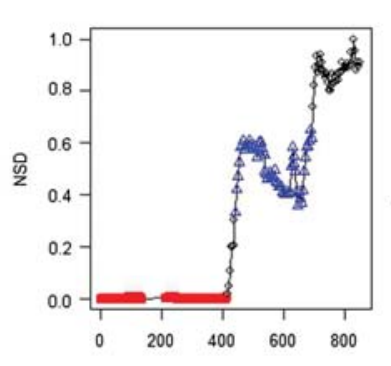
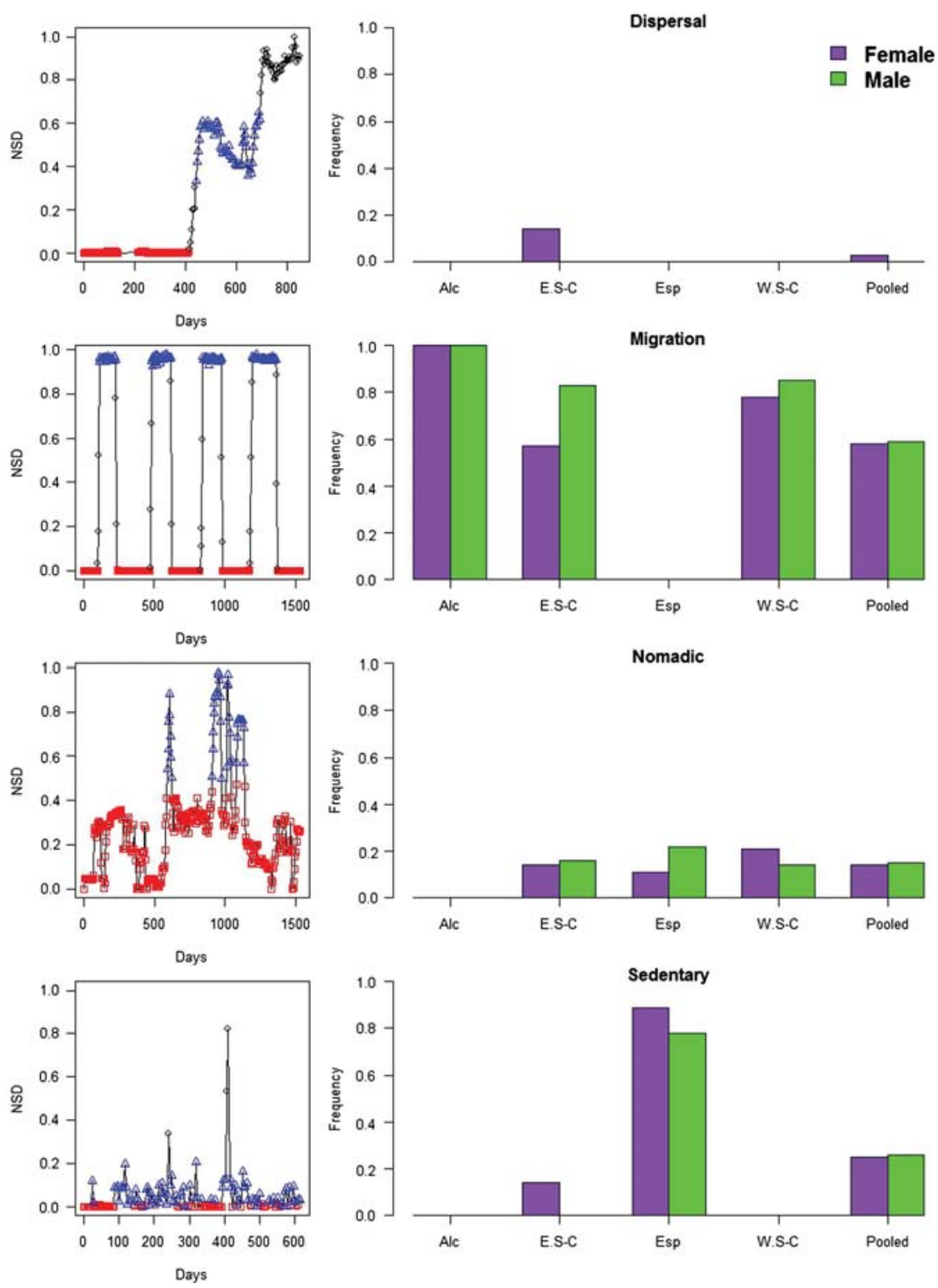

Figure 5. Illustration of movement strategies of four giant tortoises and frequency of each strategy in four species of tortoise inhabiting the Galapagos islands, 2009-2014. (A) corresponds to dispersal, (B) corresponds to migration, (C) corresponds to nomadism and (D) corresponds to residency. For each strategy, example in movement in the $x-y$ plane and the corresponding pattern in NSD are presented. Relocations are colour-associated with a specific cluster $(\mathrm{red}=1$, blue $=2$, black $=3$ ). Pattern in the probability of remaining in a given cluster $\left(\mathrm{q}_{\mathrm{ij}}\right)$ allows assignation of a different movement strategies to each individual (see Methods for further details). Frequencies are given for female and male separately and also pooled across species.

was present (Supplementary material Appendix 1 Fig. A4). Non-migratory Espanola Island tortoises departed from these generalizations, because they tended to occur in areas with lower NDVI values and higher temperatures than tortoises on other islands, which is consistent with availability within their range (Fig. 3).

\section{Annual resource selection}

The best supported models included a quadratic term for temperature, and an interaction between vegetation productivity and temperature, for both migratory and nonmigratory (i.e. dispersers, nomads and residents) individuals (Table 1). Selection patterns differed between migratory and non-migratory individuals despite overlapping in geographic space on some islands (Fig. 7, Supplementary material Appendix 1 Table A1). Migratory individuals selected areas with more predictable vegetation productivity (Fig. 7A) and temperatures (Fig. 7B) whereas non-migratory individuals avoided areas where vegetation productivity was predictable, even when they were available. Migratory individuals selected areas of temperature extremes (both colder and hotter temperatures) while avoiding areas having intermediate temperature (Fig. 7C). On an annual basis, these patterns indicate a tradeoff in selection between the colder highlands and seasonably variable but overall warmer lowlands. In colder areas, migratory individuals selected for greener vegetation, but this pattern of selection was not 

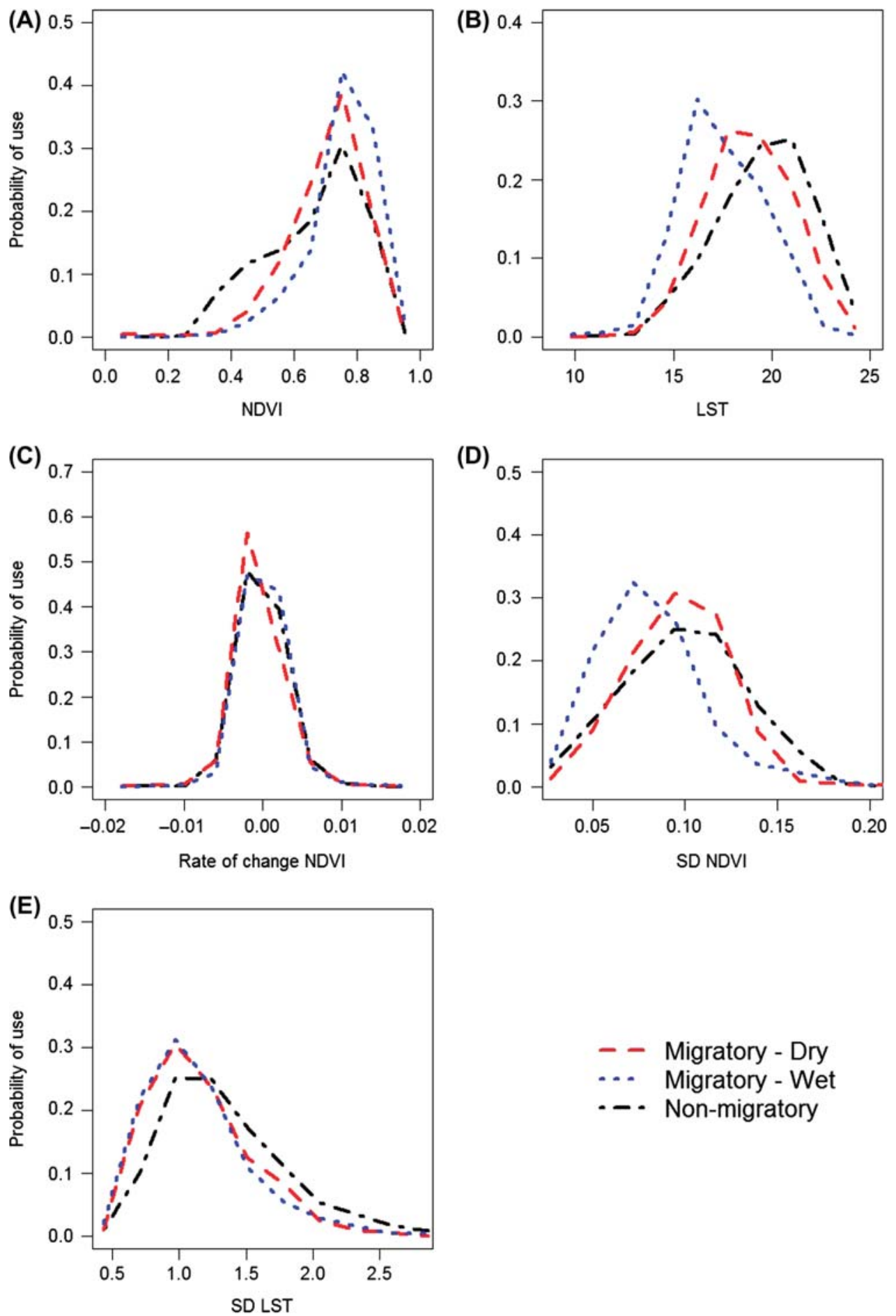

Figure 6. Probability of use of different environmental characteristics (y-axes) based on the proportion of GPS locations found areas along the listed environmental gradients (x-axes) for 63 adult giant tortoises from four different species. Environmental characteristics were extracted based on remote sensing layers from the MODIS Terra satellite. For (D) and (E), lower values of standard deviation indicate more predictable areas. See Supplementary material Appendix 1 Fig. A4 for species-specific patterns.

apparent in warmer areas (Fig. 7C). Non-migratory tortoises selected warmer areas, and areas of lower overall vegetation productivity (Fig. 7D). Results for non-migratory individuals were similar whether the largely resident population on Espanola Island was included in the analysis or not, indicating similar behavioral responses among residents of other species (Supplementary material Appendix 1 Table A1).

\section{Seasonal resource selection}

Tortoises selected locations within their cool season range that had higher levels of productivity and lower temperatures than were available at that time in their warm season range (Table 2, Fig. 8A-B, Supplementary material Appendix 1 Table A3). In their warm season ranges, tortoises selected 


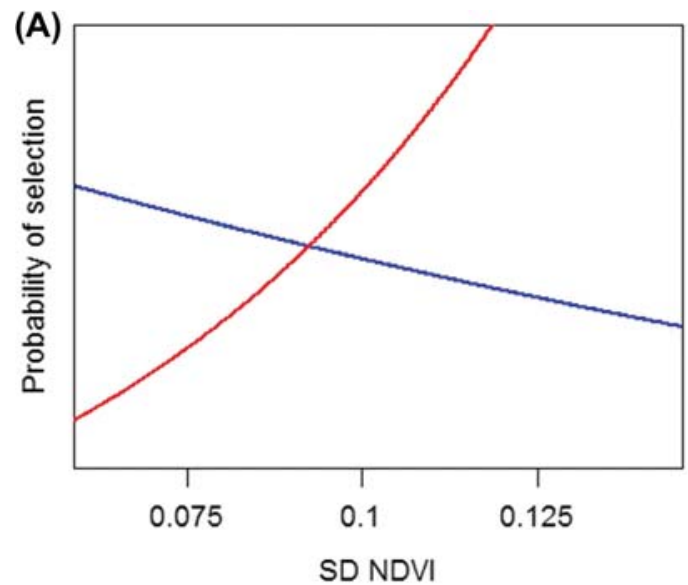

(B)
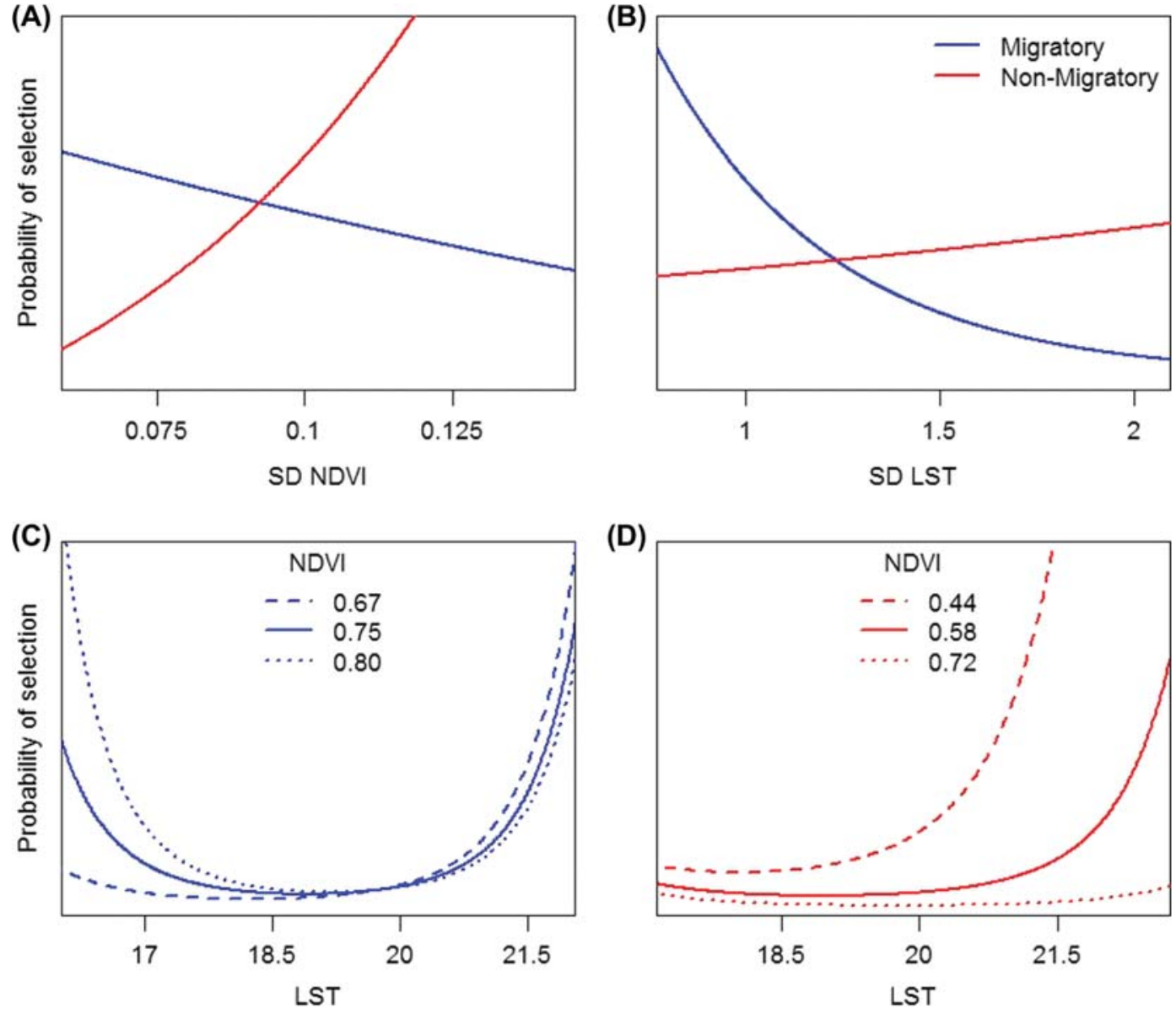

(D)

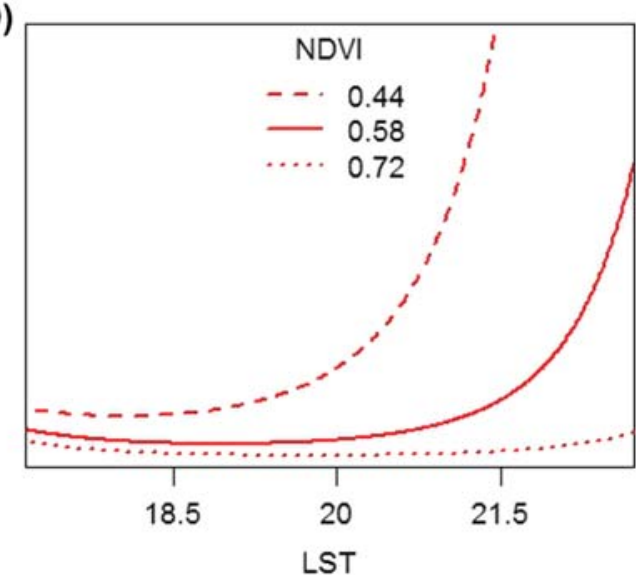

Figure 7. Patterns in relative probability of occurrence representing annual resource selection of 63 migratory and non-migratory Galapagos giant tortoises, 2009-2014. For (A) and (B), lower values of standard deviation indicate more predictable areas. Parameter estimates with confidence intervals are presented in Supplementary material Appendix 1 Table A2. Confidence intervals for the blue line in (A) and red line in (B) include zero.

locations that had the highest levels of vegetation productivity and coldest temperatures available within their warm season range at that time (Table 2, Fig. 8C, Supplementary material Appendix 1 Table A3). Moreover, during the warm season, the locations selected by tortoises corresponded to the highest temperatures available at that time in their cold season range (Table 2, Fig. 8, Supplementary material Appendix 1 Table A3).

\section{Discussion}

We introduced a framework for integrating larger-scale predictions of movement strategies with finer-scale understanding of space-use (see also Singh et al. 2010) and applied it to giant tortoises in which multiple movement strategies are observed and where predation of adults is absent. Within this taxon, we quantified strong linkages between spatiotemporal dynamics of the environment and the frequency of different movement strategies - one of few systems in which these linkages have been quantified (Singh et al. 2010, Mueller et al. 2011). Our study covers four species which are distributed across islands with very different environments, including islands with strong elevation gradients and one flat low-lying island (Espanola). Migratory individuals can exploit seasonal variation in habitat quality over a larger spatial scale than sedentary tortoises. Consistent with our predictions, migratory individuals exploited areas where vegetation productivity and temperature were more predictable than did non-migratory individuals. Local resource selection differed markedly between migratory and non-migratory tortoises, even when occupying the same physical space. In agreement with past tortoise studies using only Santa Cruz Island data (Blake et al. 2013, Yackulic et al. unpubl.), we observed that the spatio-temporal pattern in vegetation productivity also drives movement patterns of migratory individuals on Alcedo Volcano. In particular, tortoises take advantage of seasonality by moving to cooler and moister areas when the quality of vegetation in drier habitats declines to low levels. These outcomes illustrate that factors driving the propensity of individuals to migrate are key into shaping finer-scale pattern of resource selection by animals.

\section{Environmental structuring and movement strategies}

The Galapagos Archipelago is well known for its important inter-island environmental variation, which underpins the evolution of many island-specific endemic forms (Burns et al. 2002, Arbogast et al. 2006, Parent and Crespi 2006, Parent et al. 2008). Our analysis of remotely-sensed data 

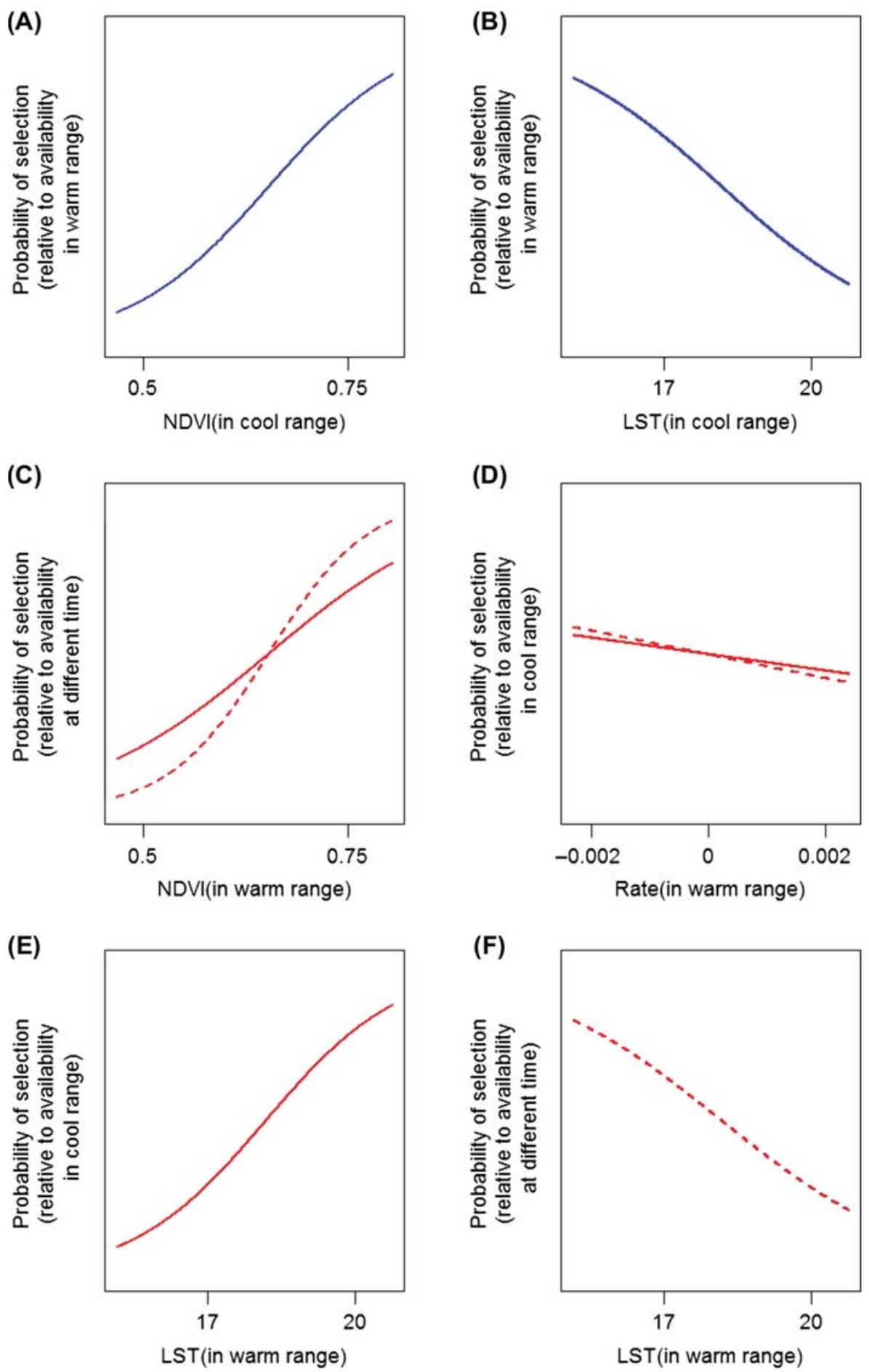

Figure 8. Patterns of seasonal resource selection of 37 migratory Galapagos giant tortoises, 2009-2014. Curves represent the relative probability of a location being selected in a given seasonal range relative to availability within that range at a different time or within their alternate seasonal range at the same time period. Blue lines represent coefficients from model 1 in Table 2. Solid and dashed red lines represent coefficients from model 5 and 6 in Table 2, respectively. Parameter estimates with confidence intervals are presented in Supplementary material Appendix 1 Table A3.

from three islands showed strong differences in the spatiotemporal structuring of vegetation productivity and, to a lesser extent, temperature. The small island of Espanola was warmer and less productive than the bigger Santa Cruz Island and Alcedo Volcano, where the presence of higher elevation areas changed the environment in several important ways. Lacking a substantial topographical gradient, Espanola Island tortoises experienced a relatively spatially homogenous but temporally less predictable environment, resulting in a prevalence of resident-to-nomadic movement strategies. In contrast, the strong gradient on Alcedo Volcano led to an entirely migratory population (at least within the range of 
body sizes we sampled). Previous work revealed both migration and residency strategies on Santa Cruz Island (Blake et al. 2013), and our movement classification algorithm, applied to daily locations, revealed a greater tendency for migration and nomadism, although both dispersal and residency were detected on Santa Cruz Island. Similar to other systems (Cagnacci et al. 2011), we found that residency and migration were the end points of a continuum of movement strategies and that many individuals displayed intermediate strategies (e.g. nomadism, exploratory residency and flexible migration strategies, Fig. 5; Bastille-Rousseau et al. 2016a).

The presence of large-scale spatio-temporal variation in environmental conditions caused principally by gradients in elevation and aspect was the single biggest explanatory factor for the frequency of movement strategies we observed - indicating the fundamental role that environmental variation plays in the evolution and maintenance of broad-scale patterns in animal movement (Mueller and Fagan 2008, Jonzén et al. 2011, Mueller et al. 2011). Herbivores are driven fundamentally by the spatio-temporal dynamics in primary productivity, a trait shared by ectothermic giant tortoises as well as large-bodied endotherms (e.g. barren-ground caribou Rangifer tarandus granti and saiga antelope Saiga tatarica; Singh et al. 2010, Mueller et al. 2011). In our analysis, the spatial gradient created by elevation yielded strongly contrasting patches of rich and poor foraging habitats, as well as predictability in the development and dynamics of vegetation productivity, which appeared to be a prerequisite for the development of migration among closely related species of tortoise. That said, given the correlative nature of our study, it remains unclear whether the greater spatio-temporal variability of vegetation productivity we observed within migratory versus resident populations was the ultimate cause of tortoise migration or a consequence of other factors limiting tortoise movements. Nevertheless, our results provide compelling evidence that large-scale patterns of vegetation dynamics influence the movement strategies of these large ectotherms similarly to terrestrial endotherms (Jonzén et al. 2011, Mueller et al. 2011).

\section{Resource selection pattern}

Our study expands upon previous work (Cagnacci et al. 2011, Bunnefeld et al. 2011, Singh et al. 2012) by assessing interactions between environmental structure and animal behavior at multiple scales. By complementing large-scale analyses of spatio-temporal structuring with fine-scale analyses of resource use and selection, we provide new insights into how animals balance the costs and benefits involved in resource acquisition. This is especially useful for assessment of resource selection in a partially migratory system. Indeed, previous attempts have sometimes shown how resident individuals normally display fine-scale selection patterns that helps them alleviate the cost of not migrating and sometime even outmatching migrants in term of fitness (Hebblewhite and Merrill 2009, Middleton et al. 2013). This is not what we observed among sedentary tortoises. Non-migratory individuals appear to be limited to less predictable areas that are warmer and poorer in annual vegetation availability, and therefore not ideal for an ectotherm. On the basis of resource selection alone, it appears that sedentarism would be a sub-optimal strategy relative to migration, though we have not included the relative energetic costs and benefits of movement.

We observed that migratory tortoises moved to their cool season range when these areas provided a more productive food base than their corresponding warm season range. Furthermore, tortoises used warm ranges when these areas were at their greenest, regardless of the level of productivity in their corresponding cool season range. This selection of recently grown vegetation is likely a consequence of newer vegetation being of higher quality than mature vegetation (forage maturition hypothesis; Fryxell 1991). Temperatures on Galapagos also approach their annual peak when tortoises forage in the warm ranges. As a result, being in the warm season ranges implied accelerated metabolic rates over being in cooler conditions, thus tortoises are able to maximize their assimilation of available forage by not remaining yearlong in the cool range (Zimmerman and Tracy 1989, Yackulic et al. unpubl.).

Our results showed that tortoises migrate between a seasonally productive and warmer area to a colder but constantly productive area but that sedentary individuals are limited to the warmer range. Previous work has shown that, within a population of tortoises, migratory individuals are typically larger than non-migratory individuals (Blake et al. 2013). Metabolic demands increase with body size, forcing larger-bodied animals to be more dependent than their smaller-bodied counterparts on areas providing consistently rich forage (Yackulic et al. unpubl.). The seasonal decline in vegetation quantity that we documented in the lower elevations could therefore be the root cause of migration in tortoises. Residency in smaller-bodied, non-migratory individuals may therefore not be a consequence of an inability of smaller-bodied individuals to migrate efficiently, but rather may be motivated by decreased sensitivity to periods of low productivity (Yackulic et al. unpubl.). It is therefore likely that what we considered as a sub-optimal strategy (i.e. sedentarism) based solely in the light of patterns of resource selection is not the case. By combining analyses of resource selection with analyses of large-scale environmental gradients, we provided a framework to contextualize the potential benefits of alternative strategies. Future research should focus on the fitness implications of individual variation in resource selection and movement patterns in order to understand the cost-benefit tradeoffs of alternative movement strategies in structured environments.

\section{Conservation implications for giant tortoises}

Animal migrations are globally threatened (Wilcove and Wikelski 2008), and several recent studies have demonstrated negative impacts on population trajectories when migration is disrupted (Hebblewhite and Merrill 2011, Middleton et al. 2013). Galapagos tortoises are vulnerable to anthropogenic pressures restricting their movements. Several taxa of Galapagos tortoise have been extirpated in the last centuries and most of the remaining taxa occur at a fraction of their former abundances (Macfarland 1974). On many islands invasive species of plants and animals threaten habitat quality for tortoises, and on inhabited islands land use change, infrastructure development and urbanization 
are changing the landscape ecology (Restrepo et al. 2012) and threatening the maintenance of long-distance tortoise migrations with potentially catastrophic implications for tortoise population trajectories (Harris et al. 2009, Holdo et al. 2011). Land management strategies that maintain migration routes and high quality habitats in both cool and warm season ranges will increase the resilience of tortoises to environmental change.

Our work illustrates the critical pathways in which vegetation dynamics influence the large-scale movement strategies and finer-scale patterns of resource selection by tortoises. Climate change may lead to more frequent and intense El Niño and La Niña episodes in the future, which can alter vegetation dramatically, particularly at lower elevations (Sachs and Ladd 2002, Restrepo et al. 2012). A concerning projection from our observations is that decreased predictability in the dynamics of vegetation development associated with climate change could favor more sedentary strategies in the future. Whether Galapagos tortoises have the behavioral flexibility to adapt rapidly to climate change on likely short temporal scales is not known, but unlikely given frequent philopatry and long generation times among chelonians.

Previous research on the interrelations among environmental dynamics, movement strategies and resource selection have generally been conducted at a single level of ecological complexity with very few studies focused on combining multiple levels (Singh et al. 2010). Here, we developed a framework to illustrate the interrelationships among ecosystem, population and individual processes that should be investigated jointly in order to better understand the tradeoffs animals face in their quest for resources (Fig. 1). Integration across levels such as our study will provide a deeper understanding of the eco-evolutionary forces at play in the emergence and maintenance of specific movement strategies, while providing a more comprehensive context for the adaptive potential of differential patterns of resource selection. To our knowledge, no previous studies that assess patterns of resource selection among migrants and residents have explicitly considered the predictability of environmental resources in their assessment of resource selection. Yet, only in the light of predictable gradients in resources assessed over a significant temporal period can the cost-benefits of migration be rigorously assessed. We see promise in future work that integrates environmental dynamics, movement strategies, and resource selection with measures of demography and, ultimately, fitness. Such an integrative framework will advance our theoretical understanding of movement ecology and, in our rapidly changing world, provide useful insights into conservation management of mobile species and their habitats.

Acknowledgements - The Galapagos National Park Service (GNPS) and Charles Darwin Foundation (CDF) provided critical technical, logistical, administrative and political support. In particular we thank Washington Tapia, Galo Quesada and Wilman Valle of the GNP, and Mark Gardener, Pilar Dias and Sonia Cisneros of the CDF. E-obs GmbH provided GPS telemetry tags at a fraction of their commercial price. Steve Devine, Herbert Frey and many other land owners on Galapagos kindly allowed us to access their property. We thank Nathaniel Rayl and Jerod Merkle for comments on an earlier version of this manuscript. Any use of trade, product, or firm names is for descriptive purposes only and does not imply endorsement by the U.S. Government.

Funding - This project was supported by the Max Planck Institute for Ornithology (Radolfzell, Germany), the National Geographic Society Committee for Research and Exploration, Galapagos Conservation Trust, Swiss Friends of Galapagos and the National Science Foundation (DEB 1258062).

\section{References}

Alerstam, T. et al. 2003. Long-distance migration: evolution and determinants. - Oikos 2103: 247-260.

Arbogast, B. S. et al. 2006. The origin and diversification of Galapagos mockingbirds. - Evolution 60: 370-382.

Ball, J. et al. 2001. Partial migration by large ungulates: characteristics of seasonal moose Alces alces ranges in northern Sweden. - Wildlife Biol. 7: 39-47.

Bastille-Rousseau, G. et al. 2015. Unveiling tradeoffs in resource selection of migratory caribou using a mechanistic movement model of availability. - Ecography 38: 1049-1059.

Bastille-Rousseau, G. et al. 2016a. Flexible characterization of animal movement pattern using net squared displacement and a latent state model. - Movement Ecol. 4: 15.

Bastille-Rousseau, G. et al. 2016b. Allometric and temporal scaling of movement characteristics in Galapagos tortoises. - J. Anim. Ecol. 85: 1171-1181.

Bastille-Rousseau, G. et al. 2016c. Data from: Flexible characterization of animal movement pattern using net squared displacement and a latent state model. - Movebank Data Repository. doi: $10.5441 / 001 / 1.356 \mathrm{nb} 5 \mathrm{mf}$.

Bastille-Rousseau, G. et al. 2016d. Data from: Animal movement in the absence of predation: environmental drivers of movement strategies in a partial migration system. - Figshare Data Repository. doi: 10.6084/m9.figshare. 4480202 .

Bischof, R. et al. 2012. A migratory northern ungulate in the pursuit of spring: jumping or surfing the green wave? - Am. Nat. 180: 407-424.

Blake, S. et al. 2012. Seed dispersal by Galápagos tortoises. - J. Biogeogr. 39: 1961-1972.

Blake, S. et al. 2013. Vegetation dynamics drive segregation by body size in Galapagos tortoises migrating across altitudinal gradients. - J. Anim. Ecol. 82: 310-321.

Boyce, M. S. 2006. Scale for resource selection functions. - Divers. Distrib. 12: 269-276.

Boyce, M. S. et al. 2002. Evaluating resource selection functions. - Ecol. Modell. 157: 281-300.

Boyle, W. A. 2008. Partial migration in birds: tests of three hypotheses in a tropical lekking frugivore. - J. Anim. Ecol. 77: $1122-1128$.

Bunnefeld, N. et al. 2011. A model-driven approach to quantify migration patterns: individual, regional and yearly differences. - J. Anim. Ecol. 80: 466-576.

Burnham, K. P. and Anderson, D. R. 2002. Model selection and multimodel inference. - Springer.

Burns, K. J. et al. 2002. Phylogenetic relationships and morphological diversity in Darwin's finches and their relatives. - Evolution 56: 1240-1252.

Caccone, A. et al. 2002. Phylogeography and history of giant Galápagos tortoises. - Evolution 56: 2052-2066.

Cagnacci, F. et al. 2011. Partial migration in roe deer: migratory and resident tactics are end points of a behavioural gradient determined by ecological factors. - Oikos 120: 1790-1802.

Chapman, B. B. et al. 2011. The ecology and evolution of partial migration. - Oikos 120: 1764-1775.

Congdon, J. D. et al. 1993. Delayed sexual maturity and demographics of blanding turtles (Emydoidea-Blandingii) 
- implications for conservation and management of long-lived organisms. - Conserv. Biol. 7: 826-833.

Fleming, C. H. et al. 2014. From fine-scale foraging to home ranges: a semivariance approach to identifying movement modes across spatiotemporal scales. - Am. Nat. 183: E154-E167.

Fritts, T. H. 1983. Morphometrics of Galapagos tortoises: evolutionary implications. - In: Bowman, R. et al. (eds), Patterns of evolution in Galapagos organisms. AAAS Pacific Division, pp. 107-122.

Fryxell, J. M. 1991. Forage quality and aggregation by large herbivores. - Am. Nat. 138: 478-498.

Fryxell, J. M. et al. 1988. Why are migratory ungulates so abundant? - Am. Nat. 131: 781-798.

Harris, G. et al. 2009. Global decline in aggregated migrations of large terrestrial mammals. - Endanger. Species Res. 7: 55-76.

Hebblewhite, M. and Merrill, E. H. 2009. Tradeoffs between predation risk and forage differ between migrant strategies in a migratory ungulate. - Ecology 90: 3445-3454.

Hebblewhite, M. and Merrill, E. H. 2011. Demographic balancing of migrant and resident elk in a partially migratory population through forage-predation tradeoffs. - Oikos 120: $1860-1870$

Hebblewhite, M. et al. 2008. A multi-scale test of the forage maturation hypothesis in a partially migratory ungulate population. - Ecol. Monogr. 78: 141-166.

Hird, J. N. and McDermid, G. J. 2009. Noise reduction of NDVI time series: an empirical comparison of selected techniques. - Remote Sens. Environ. 113: 248-258.

Hnatiuk, S. H. 1978. Plant dispersal by the Aldabran giant tortoise, Geochelone gigantea (Schweigger). - Oecologia 36: 345-350.

Holdo, R. M. et al. 2011. Predicted impact of barriers to migration on the Serengeti wildebeest population. - PLoS ONE 6: e16370.

Jahn, A. E. et al. 2010. Determinants of partial bird migration in the Amazon Basin. - J. Anim. Ecol. 79: 983-992.

Johnson, D. H. 1980. The comparison of usage and availability measurements for evaluating resource preference. - Ecology 61: 65-71.

Jonzén, N. et al. 2011. Uncertainty and predictability: the niches of migrants and nomads. - In: Milner-Gulland, E. J. et al. (eds), Animal migration: a synthesis. Oxford Univ. Press, pp. 91-109.

Julien, Y. and Sobrino, J. A. 2010. Comparison of cloud-reconstruction methods for time series of composite NDVI data. - Remote Sens. Environ. 114: 618-625.

Justice, C. O. et al. 1998. The moderate resolution imaging spectroradiometer (MODIS): land remote sensing for global change research. - IEEE Trans. Geosci. Remote Sens. 36: 1228-1249.

Kaitala, A. et al. 1993. A theory of partial migration. - Am. Nat. 142: 59-81.

Macfarland, C. G. 1974. The galapagos giant tortoises Geochelone elephantopus status of the surviving populations. - Biol. Conserv. 6: 118-133.

Merkle, J. A. et al. 2016. Large herbivores surf waves of green-up in spring large herbivores surf waves of green-up during spring. - Proc. R. Soc. B 283: 20160456.

Merton, L. F. H. et al. 1976. Giant tortoise and vegetation interactions on aldabra atoll - Part 1: Inland. - Biol. Conserv. 9: 293-304.

Middleton, A. D. et al. 2013. Animal migration amid shifting patterns of phenology and predation: lessons from a Yellowstone elk herd. - Ecology 94: 1245-56.
Mueller, T. and Fagan, W. 2008. Search and navigation in dynamic environments - from individual behaviors to population distributions. - Oikos 177: 654-664.

Mueller, T. et al. 2011. How landscape dynamics link individualto population-level movement patterns: a multispecies comparison of ungulate relocation data. - Global Ecol. Biogeogr. 20: 683-694.

Parent, C. E. and Crespi, B. J. 2006. Sequential colonization and diversification of Galapagos endemic land snail genus bulimulus (Gastropoda, Stylommatophora). - Evolution 60: 2311-2328.

Parent, C. E. et al. 2008. Colonization and diversification of Galápagos terrestrial fauna: a phylogenetic and biogeographical synthesis. - Phil. Trans. R. Soc. B 363: 3347-3361.

Pettorelli, N. et al. 2005. Using the satellite-derived NDVI to assess ecological responses to environmental change. - Trends Ecol. Evol. 20: 503-510.

Pettorelli, N. et al. 2007. Early onset of vegetation growth vs rapid green-up: impacts on juvenile mountain ungulates. - Ecology 88: $381-390$.

Poulakakis, N. et al. 2015. Description of a new Galapagos giant tortoise species (Chelonoidis; Testudines: Testudinidae) from Cerro Fatal on Santa Cruz Island. - PLoS ONE 10: e0138779.

Restrepo, A. et al. 2012. Impacts of climate variability and human colonization on the vegetation of the Galápagos Islands. - Ecology 93: 1853-1866.

Russello, M. A. et al. 2005. A cryptic taxon of Galápagos tortoise in conservation peril. - Biol. Lett. 1: 287-290.

Sachs, B. J. P. and Ladd, S. N. 2002. Climate and oceanography of the Galapagos in the 21st century : expected changes and research needs. - Galápagos Res. 67: 50-54.

Singh, N. J. et al. 2010. Tracking greenery across a latitudinal gradient in central Asia - the migration of the saiga antelope. - Divers. Distrib. 16: 663-675.

Singh, N. J. et al. 2012. From migration to nomadism: movement variability in a northern ungulate across its latitudinal range. - Ecol. Appl. 22: 2007-2020.

Stevenson, R. D. 1985. The relative importance of behavioral and physiological adjustments controlling body temperature in terrestrial ectotherms. - Am. Nat. 126: 362-386.

Swingland, I. R. and Coe, M. J. 1979. The natural regulation of giant tortoise populations on aldabra atoll: recruitment. - Phil. Trans. R. Soc. B 286: 177-188.

Trueman, M. and d'Ozouville, N. 2010. Characterizing the Galapagos terrestrial climate in the face of global climate change. - Galapagos Res. 67: 26-37.

Trueman, M. et al. 2013. Interdisciplinary historical vegetation mapping for ecological restoration in Galapagos. - Landsc. Ecol. 28: 519-532.

Wang, W. et al. 2008. Validating MODIS land surface temperature products using long-term nighttime ground measurements. - Remote Sens. Environ. 112: 623-635.

Watson, J. et al. 2009. Mapping terrestrial anthropogenic degradation on the inhabited islands of the Galapagos Archipelago. - Oryx 44: 79-82.

Wilcove, D. S. and Wikelski, M. 2008. Going, going, gone: is animal migration disappearing. - PLoS Biol. 6: e188.

Yackulic, C. B. et al. 2014. A quantitative life history of endangered humpback chub that spawn in the Little Colorado River: variation in movement, growth and survival. - Ecol. Evol. 4: 1006-18.

Zar, J. H. 2009. Biostatistical analysis, 5th edn. - Prentice Hall.

Zimmerman, L. C. and Tracy, C. R. 1989. Interactions between the environment and ectothermy and herbivory in reptiles. - Physiol. Zool. 62: 374-409. 